\title{
Probability Theory and Mathematical Statistics E-course in Nomotex DLS
}

\author{
Yury I. Dimitrienko ${ }^{1}$, Tatyana V. Oblakova ${ }^{1 *}$, Kirill M. Zubarev ${ }^{1}$, and Anna A. Salnikova ${ }^{1}$ \\ ${ }^{1}$ Bauman Moscow State Technical University, 2nd Baumanskaya str., 5/1, 105005, Moscow, Russia
}

\begin{abstract}
The paper considers the concept of constructing Probability Theory and Mathematical Statistics electronic course for interactive learning. The approach to the design of the e-course is described, and the advantages of using the new teaching technology in the Digital Learning System Nomotex, developed at the Department of Computational Mathematics and Mathematical Physics of the Bauman Moscow State Technical University, are demonstrated.
\end{abstract}

\section{Introduction}

The Digital Learning System (DLS) Nomotex, created at the Department of Computational Mathematics and Mathematical Physics of Bauman Moscow State Technical University, is an original development of the Department and is designed to implement a model of digital-classroom learning. The innovative principles and techniques underlying this model are described in detail in the works [1-4].

This work describes probability theory and mathematical statistics course development in the DLS Nomotex framework and analyses its features.

\section{The design of Probability Theory and Mathematical Statistics course in the DLS Nomotex environment}

Due to the widespread demand in the digital age for skills and abilities to work with large amounts of information (big data), Probability Theory and Mathematical Statistics (PTMS) e-courses [5], [6] are an integral part of the curricula of the vast majority of specialties and training areas for engineers, economists, biologists, and financiers (see http://fgosvo.ru). An important feature of probabilistic disciplines conducted both at the department represented by the authors and at the University as a whole is their wide variety in the range from short two-credits introductory courses to a two-semester sequential detailed and advanced course that implies the acquisition of programming skills for statistical modelling. In recent decades, all leading universities, including BMSTU, have been actively working to modernize their courses [7-13].

Nowadays, it is particularly important to construct a course according to the scope and required set of student's competencies [14-19]. The DLS Nomotex platform provides a

* Corresponding author: obltv@inbox.ru 
convenient way to design a course. At this stage, the amount of entered material (see figure 1,2) allows one to create Probability Theory and Mathematical Statistics e-courses in the range from two to five credit points.
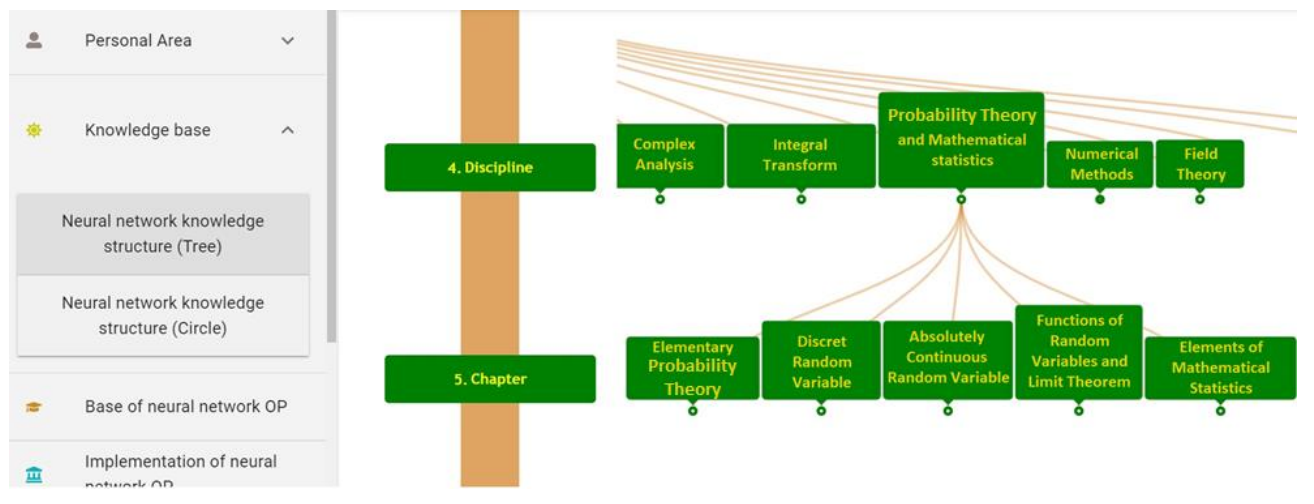

Fig. 1. Structure of the PTMS e-course in the DLS Nomotex: division into chapters.

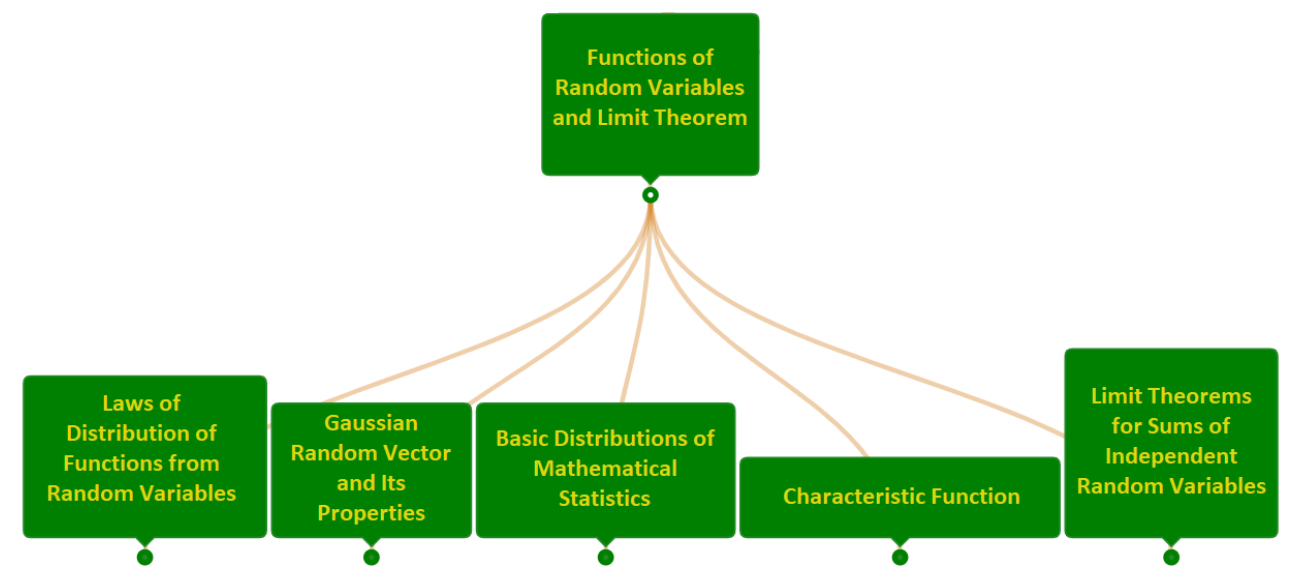

Fig. 2. Structure of Chapter 4 of PTMS e-course: division into paragraphs.

\section{An example of interactive-mode learning for the Gaussian model}

Let us consider the advantages of the implemented interactive learning format using as an example the study of a two-dimensional Gaussian model in the DLS Nomotex. The stated topic is the content of the section "Gaussian random vector and its properties", which consists of six elements (quanta) with links to other elements of the course and the ability to use reference information (for example, table values of the Laplace function).

After presenting theoretical information in the form of a lecture with either full, partial or no proof at all, depending on the course, students, under the guidance of a teacher or as part of independent work, consolidate their knowledge by working with the interactive training scheme. Usually this scheme is accompanied by graphic and / or multimedia illustrations.

Figure 3 shows a visualization of the concept of conditional density in the Gaussian case. Students have the ability to vary parameters and track changes in the density graphs. 


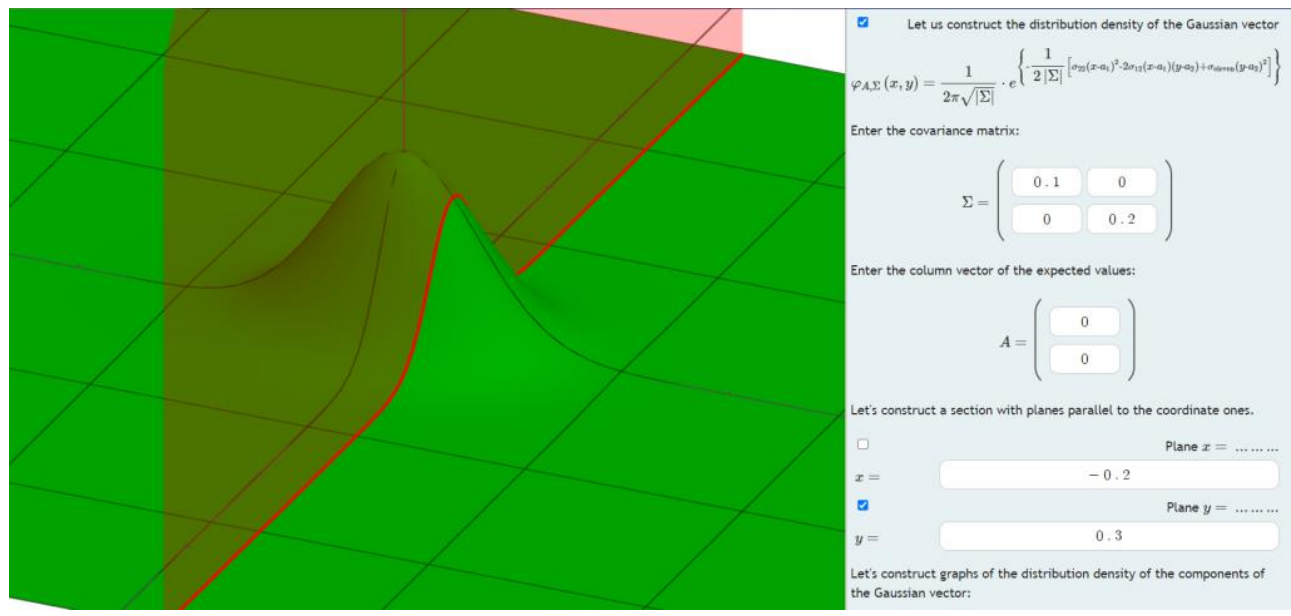

Fig. 3. Working with two-dimensional Gaussian density in DLS Nomotex.

Figure 4 shows the training element on the topic «Central limit theorem».

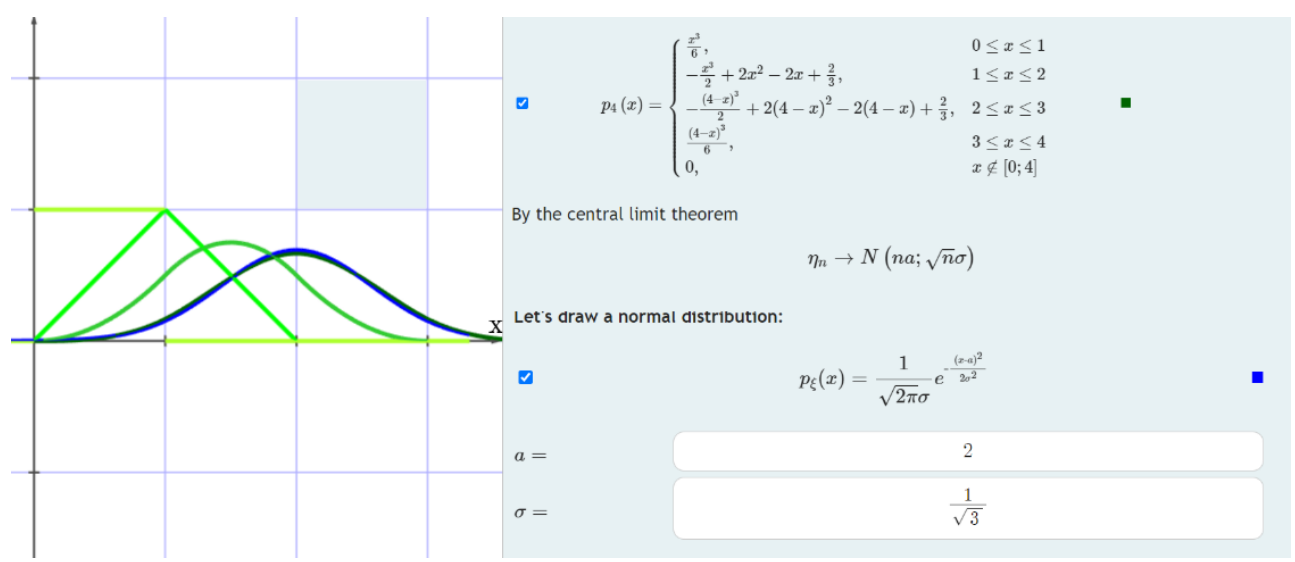

Fig. 4. Training the «Birth of the Gaussian law» in of PTMS e-course.

\section{Organization of students' practical work in the DLS Nomotex}

In accordance with the established principles, all classroom lessons, including tests, are held in equipped classrooms with maximum immersion in the computer-based learning process. Students have the opportunity to immediately check the correctness of the solution after completing the task, and, if necessary, correct and re-check the answer and / or get advice from the teacher. The teacher, on his /her part, in real time sees on his computer screen the results of the students' work, the number of solved problems, and their correctness (Fig. 5). 
Independent work No. 1

Ticket number 7200

Delivery time: $04.11 .2020,12: 01: 52$

\begin{tabular}{|c|c|c|c|c|c|}
\hline \multicolumn{3}{|l|}{ Problem 1} & \multicolumn{3}{|l|}{ Problem 2} \\
\hline$\frac{\text { Exercise }}{1}$ & 7 points & $\begin{array}{l}\text { Delivery time: } 04.11 .2020,12: 01: 52 \\
\text { Option: } 2 \\
\text { Answer: Condition: } \\
\text { Random variables } \xi \text { and } \eta \text { are independent and both are } \\
\text { distributed according to the standard normal law with } \\
\text { density } \varphi_{0,1}(x)=\frac{1}{\sqrt{2 \pi}} e^{-\frac{1}{2} x^{2}} \ldots \text { Write down the formula } \\
\text { for joint density } p_{\xi, \eta}(x, y) \text { and calculate the variance of } \\
\text { the random variable } \zeta=\xi-\eta \ldots \\
\text { Answer: } \\
\qquad p_{\xi \eta}(x, y)=\frac{1}{2 \pi} \cdot e^{\left(\frac{\left(-x^{2}-y^{2}\right)}{2}\right)} \\
\qquad D(\zeta)=2\end{array}$ & $\begin{array}{l}\frac{\text { Assignment }}{2} \\
\underline{2}\end{array}$ & 7 points & $\begin{array}{l}\text { Delivery time: } \\
04.11 .2020, \\
12: 01: 52 \\
\text { Option: } 3 \\
\text { Answer: Condition: } \\
\text { It is known that } \\
M \xi=3, D \xi=1 \text {, } \\
M \eta=-1, \\
D \eta=2, \\
\operatorname{cov}(\xi, \eta)=-0.5 . \\
\text { Random value } \\
\zeta=2 \eta-3 \xi+2 . \\
\text { Find its variance } \\
D(2 \eta-3 \xi+2) \text {... } \\
\text { Answer: } \\
\qquad D(\zeta)=23\end{array}$ \\
\hline
\end{tabular}

Fig. 5. Representation of the student's task-completion result in the Personal-account window in the DLS Nomotex.

\section{Principles of creating and operating a database of problems and test questions on probability theory and mathematical statistics}

The described form of the lesson assumes the presence of a large database of tasks and test questions, distributed according to the topics of training sessions and ranked by difficulty. From these tasks, provided there is a sufficient number of them, it is possible to randomly generate both practice and test papers. Moreover, the database of exercises is compelety open. If the student has solved the problem, then he [/she] can enter the answer and check its correctness. The more tasks he [/she] solved, the higher his [/her] chances of getting high marks. At this stage, the process of database development is underway.

Figure 6 shows an example of a test question. After completing the work and passing the test, the student immediately sees his[/her] result.

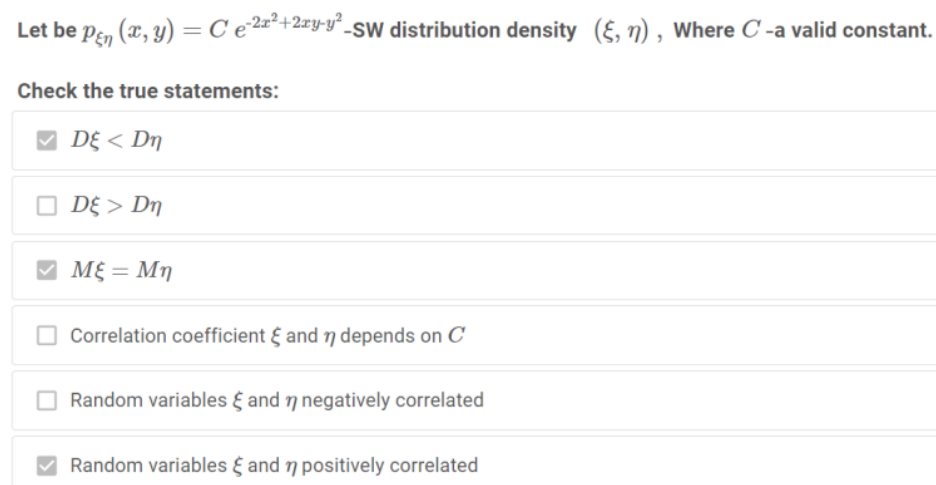

Fig. 6. Example of a test question for density properties in PTMS e-course. 


\section{Conclusions}

Currently, the development of the general Probability Theory and Mathematical Statistics e-course in DLS Nomotex is practically completed in terms of creating a database of theoretical information. At the same time the work to enlarge the database of tasks and test questions and to create new interactive training content is underway. In test mode, the course was conducted for various student's groups in 2018-2020. Conclusive results will be obtained in a few years, after the full-scale implementation of the course, but already now, we note the undoubtedly increased interest of the students in studying the subject.

\section{References}

1. Yu. Dimitrienko, E. Gubareva, New technology of mathematical training of engineering personnel, based on a neural network model of knowledge, Innovation in education, № 11, pp. 129-140 (2017)

2. Yu. Dimitrienko, E. Gubareva, Hierarchical neural network model for mathematical knowledge and software NOMOTEX for mathematical training of engineers, IOP Journal of Physics: Conference Series, volume 1141012010 doi:10.1088/17426596/1141/1/012010 (2018)

3. All-Russian seminar "New digital technologies for the mathematical training of engineering personnel" [Electronic resource]. URL: http://www.bmstu.ru/mstu/news/news.html?newsid=4556 (accessed: 10/15/2018).

4. E.T. Kitova, E.G. Skibitsky, Information and educational environment of the university - a toolkit for improving the level of students' training Innovations in education, № 10, pp. 116-125 (2016)

5. G.I. Ivchenko, Yu.I. Medvedev, Mathematical Statistics: Textbook, M.: Book House "LIBROCOM", pp. 219, 352.

6. N.Yu. Enatskaya, E.R. Khakimullin, Probability theory and mathematical statistics for engineering directions: a textbook and a workshop for applied undergraduate studies, M.: Yurayt Publishing House, pp. 399 (2015)

7. I.D. Dinov, J. Sanchez, N. Christou, Pedagogical utilization and assessment of the statistic online computational resource in introductory probability and statistics courses, Computers \& Education, 50(1), pp. 284-300 (2008)

8. Q. Zhang, F.C. Bonafini, B.B. Lockee, K.W. Jablokow, X. Hu, Exploring demographics and students' motivation as predictors of completion of a massive open online course, International Review of Research in Open and Distributed Learning, 20(2), (2019)

9. L. Gao, X. Sun, Online Teaching Management and Practice of "Probability Theory and Mathematical Statistics" Course-Take Bengbu University for Example, Advances in Education, 10, 861

10. I.D. Dinov, J. Sanchez, N. Christou, Central limit theorem: New SOCR applet and demonstration activity, Journal of Statistics Education, 16(2) (2008)

11. P.M. Wood, V. Bhute, Exploring Student Perception Toward Online Homework and Comparison With Paper Homework in an Introductory Probability Course, Journal of College Science Teaching, 48(5), pp. 68-75 (2019)

12. N.M. Mezhennaya, O.V. Pugachev, Advantages of Using the CAS Mathematica in a Study of Supplementary Chapters of Probability Theory, European Journal of Contemporary Education, 8(1), pp. 4-24, (2019) 
13. E. Mochalina, G. Ivankova, O. Tatarnikov, Advanced teaching module for the course" Theory of Probability and Statistics" based on a recurrent test system with an incremental level of complexity and dynamical case studies, In 4th International Conference on Higher Education Advances (HEAD'18), pp. 597-604 (2018)

14. V. Gromyko, V. Kazaryan, N. Vasilyev, A. Simakin, S. Anosov, Artificial intelligence as tutoring partner for human intellect, Advances in intelligent systems and computing, № 658, pp. 238-247 (2018)

15. V. Mayorova, O. Zhdanovich, Innovative collaborative educational programs for space systems engineers, Proceedings of the International Astronautical Congress, IAC (2016)

16. G. Procurat, A. Strukova, A. Vukolov, O. Egorova, Generated graphics and game development software in engineering education: Perspectives and experience of usage, Mechanisms and Machine Science, № 64, pp. 123-130 (2019)

17. N. Serdyukova, V. Serdyukov, S. Neustroev, Testing as a feedback in a smart university and as a component of the identification of smart systems, Smart Innovation, Systems and Technologies, № 144, pp. 527-538 (2019)

18. V. Guznenkov, P. Zhurbenko, The Academic Discipline 'Computer Graphics' for the Open Education System, 2018 4th International Conference on Information Technologies in Engineering Education, Inforino 2018 - Proceedings 8581738 (2018)

19. A. Karpov, Education for knowledge society: Learning and scientific innovation environment, Journal of Social Studies Education Research, № 8(3), pp. 201-214 (2017) 